\title{
AKT1 Gene Alteration Positive
}

National Cancer Institute

\section{Source}

National Cancer Institute. AKT1 Gene Alteration Positive. NCI Thesaurus. Code C146651.

A finding indicating that mutation, overexpression or rearrangement of the AKT1 gene has been detected in a sample. 